\title{
Health Behaviors, Periodontal Conditions, and Periodontal Pathogens in Spontaneous Preterm Birth: A Case-Control Study in Korea
}

Jae-In Ryu, ${ }^{*}$ KyungJoon Oh, ${ }^{\dagger}$ HyeJin Yang, ${ }^{\dagger}$ Bong-Kyu Choi, ${ }^{\ddagger} \S$ Jung-Eun Ha,,$\|$ Bo-Hyoung Jin, $₫ \|$ Hyun-Duck Kim, $\$ \|$ and Kwang-Hak Bae ${ }^{\S \|}$

Background: This study aims to determine whether periodontal conditions or dental health behaviors are risk factors for preterm birth (PTB), and whether periodontal pathogens are risk indicators for PTB among Korean mothers.

Methods: This study was designed as a hospital-based case-control study. Examiner masking was ensured for the validity of the examinations. The mothers included those who gave birth between November 2007 and July 2009 at the obstetrics clinic of a general hospital in Seoul, Korea. Information on demographic and health conditions, periodontal conditions, and microbacterial data was collected.

Results: A total of 172 women met the inclusion criteria, 59 mothers who delivered a preterm neonate were assigned to the case group while the other 113 were assigned to the control group. There were no significant differences in demographic information, oral health conditions, and obstetric characteristics. Among health-related behaviors, only scaling within 12 months before pregnancy showed a significant difference $(P=0.031)$. Even in the adjusted logistic model, only the difference in the experience of scaling before pregnancy was significant between the PTB cases and the controls $(P=$ 0.039). Periodontal disease did not exhibit a significant relationship with PTB even after adjustment for potential confounding factors. Among the microbacterial factors, only Porphyromonas gingivalis showed a slight difference $(P=0.060)$.

Conclusion: There was a significant difference in scaling experience within 12 months before pregnancy and $P$. gingivalis showed a marginal difference between the PTB and the control groups but clinical periodontal conditions showed no association with PTB. J Periodontol 2010;81:855-863.

\section{KEY WORDS}

Periodontal disease; pregnancy complications; risk factors.

* Oral Health Promotion Supporting Committee, Korea Institute for Health and Social Affairs, Seoul, Korea.

$\dagger$ Department of Obstetrics and Gynecology, Seoul National University College of Medicine, Seoul, Korea.

‡ Department of Oral Microbiology and Immunology, School of Dentistry, Seoul National University, Seoul, Korea.

$\S$ Dental Research Institute, School of Dentistry, Seoul National University.

II Department of Preventive and Public Health Dentistry, School of Dentistry, Seoul National University.
$\mathrm{P}$ reterm delivery and low birth weight (PLBW) are main risk factors of infant mortality and a major public health problem. Preterm birth (PTB) is defined as delivery at $<37$ weeks and low birth weight as $<2,500$ g. ${ }^{1}$ Over $60 \%$ of perinatal mortality (except for anatomic and genetic abnormalities) is caused by PTB and low birth weight. Preterm infants have higher risks of respiratory disease, cardiovascular problems, epilepsy, and severe learning disorders than full-term infants. ${ }^{2-4}$ As a result, countries devote considerable financial resources to prevent PLBW and related diseases.

The World Health Organization ${ }^{5}$ reported that the incidence of low birth weight ranges from 8\% in Europe to $26.2 \%$ in Southeast Asia. The rate of PTB in Korea has increased steadily from $4.3 \%$ in 1995 to $7 \%$ in $1998,8.3 \%$ in 2000 , and $10 \%$ in $2003 .{ }^{6}$ It has become a more severe problem because the overall birth rate has dropped dramatically from $6 \%$ in 1960 to $3.6 \%$ in 1974 and $1.1 \%$ in 2005.7

Several factors are known to contribute to PLBW (e.g., smoking, 
drinking, drug abuse, infection of the reproductive and urinary organs, hypertension, gestational diabetes, and socioeconomic or educational disadvantages that might affect responsible self-awareness with regards to pre-pregnancy health).$^{8-12}$ During the 1980s, it was concluded that maternal periodontal infection might be related to PLBW. ${ }^{13}$ A study showed that pregnant hamsters subcutaneously infected with Porphyromonas gingivalis tended to produce low birth weight pups. ${ }^{14}$ Several studies with case control and cohort revealed an association between periodontal infection and PLBW. ${ }^{15-19}$ Three hypotheses that may explain the relationship between periodontal infection and PLBW are as follows: 1) periodontal pathogens cause direct contamination in the fetoplacental unit;20 2) lipopolysaccharide, a bacterial endotoxin normally found in infected periodontal tissue, is released and acts on the fetoplacental unit through the blood; ${ }^{19-21}$ and 3) inflammatory mediators from an infected periodontal reservoir provoke problems in the fetoplacental unit. ${ }^{19-21}$

Recently, however, Davenport et al. ${ }^{22}$ suggested that it was not feasible to detect a significant relationship between periodontal infection and PLBW in a study with 507 subjects in the control group and 236 in the case group. Although the pathogenic bacteria of periodontitis are likely to cause PLBW, the relationship between PLBW and periodontal disease has not been definitively proven. ${ }^{20,23}$ A Spanish study also reported that there is no significant relationship between gestational age and periodontal parameters or between low-weight delivery and plaque index. ${ }^{24}$ At the same time, Lunardelli and Peres ${ }^{25}$ showed that the condition of the periodontal pocket is not significantly associated with low birth weight or PTB after controlling maternal health variables. A Brazilian study advocated that determinants other than periodontal disease and health conditions may explain the lack of significance. ${ }^{26}$

A study in Sri Lanka proposed that the relationship between periodontal health and PLBW may differ by region and population. ${ }^{27}$ Even in randomized controlled trials, Lopez et al. ${ }^{17}$ concluded that periodontal therapy during pregnancy may reduce the incidence of preterm delivery, but Offenbacher et al. ${ }^{28}$ reported opposite results from periodontal therapy. They raised some issues related with intervention studies, such as the time, method, and level of interventions. The association of periodontal infection with PLBW is still controversial and the differences may be caused by ethnic and cultural environments. A case-control study including variables about the use of dental services before and during pregnancy can provide a significant clue to help design randomized controlled trials.

Therefore, this study was performed to determine whether periodontal conditions or dental health be- haviors are risk factors (or indicators) for PLBW, and whether periodontal pathogens are risk indicators (or predictors) for PLBW among Korean mothers.

\section{MATERIALS AND METHODS}

\section{Study Design and Subject Sampling}

This study was designed as a hospital-based casecontrol study. Examiner masking was ensured for the validity of the examinations by the two obstetricians (KJO, HJY), Seoul National University Hospital, Seoul, Korea. Both examiners were responsible for selection and diagnosis of the subjects in this study. The study was conducted in compliance with the principles of the Helsinki Declaration. Ethical clearance of the study was approved by the Institutional Review Board of Seoul National University Hospital (Institutional Review Board no. H-0709-046-219).

The study sample included mothers who gave birth between November 2007 and July 2009 at the obstetrics clinic of a general hospital in Seoul, Korea. Only mothers with a single birth and spontaneous PTB were included as cases. Those with systemic conditions related to PTB, such as hypertension, diabetic disorder, cardiovascular disease, and active hepatic disease, were excluded. The control group was sampled by matching the following conditions with the PTB cases: age between $<3$ years and $>3$ years than the case and delivery mode, such as vaginal delivery versus caesarean section. All the study subjects provided their written informed consent before participation.

The appropriate sample size for this study was calculated using the power and sample size calculation program. ${ }^{29}$ In this program, a dichotomous output with an independent case-control study was modeled to identify the sample size sufficient to detect the difference between two odds ratios. We used the following inputs to calculate the sample size: 1 ) type I error probability for a two-sided test $(\alpha)$ of $0.05 ; 2$ ) a power (probability of correctly rejecting the null hypothesis) of 0.80 $(1-\beta)$, chosen so that the relative risk (odds ratio) equals to 1 given $n$ cases and $m$ control patients; 3 ) probability of exposure in controls $\left(p_{0}\right)$ of $\left.0.2 ; 4\right)$ a ratio of control to case patients $(m)$ of 2 ; and 5 ) an odds ratio of exposure in cases relative to controls $(\psi)$ of 3 . We obtained the following sample size by applying these inputs: 138 subjects including 46 case patients and 92 control patients. This size was multiplied by 1.2 to account for possible loss of subjects or data, resulting in a minimum total sample size of 166 . In the end, 187 pregnant women (64 cases and 123 controls) were invited to participate in the study. Among them, 15 (5 cases and 10 controls) were excluded because of their systemic conditions; therefore, 172 (59 cases and 113 controls) were included in this study. 


\section{Clinical Examinations}

Demographic and health information. A trained interviewer (JEH) asked all the patients about demographic information; i.e., their general and oral health histories; medications; diet; weight gain during pregnancy; health-related behavior before and during pregnancy, such as smoking and drinking; and oral health treatment experience before and during pregnancy. The family history related to pregnancy, obstetric information including the number of offspring, and pregnancies or abortions, and medical history including systemic disease were obtained by the case report form through a medical record chart.

Oral examination. The examinations were conducted by one trained dentist (KHB) using dental mirrors and focusable optimal light while the patients rested in the hospital bed. The participants were examined 2 to 5 days after delivery. The periodontal attachment loss of all the teeth except the third molars and distal sites of second molars were measured by probing with $20 \mathrm{~g}$ power, including mesio-buccal, mid-buccal, disto-buccal, disto-lingual, mid-lingual, and mesio-lingual surfaces. Walking probing method (up and down movement following the base of the pocket in order to avoid damaging the periodontal tissue) was used for continuous measurement. A periodontal probe was used in this study." Bleeding on probing (BOP) was noted about 30 to 60 seconds after probing. A patient was determined to have periodontitis when $\geq 2$ teeth showed clinical periodontal attachment loss $>3.5 \mathrm{~mm}$, and to have gingivitis when $\geq 25 \%$ of sites showed BOP.

Microbacterial examination. Subgingival biofilm and gingival crevicular fluid (GCF) were taken from selected members of the study group. The selection process was as follows: 1) those who had taken antibiotics to control PTB were excluded, 2) mothers who underwent a natural childbirth were selected first, and then 3) a group of patients were selected at random from those satisfying conditions one and two. One of two controls was selected at random per case for microbacterial examination.

Sampling GCF and subgingival bacteria. GCF and subgingival plaque samples were collected together from the mesio-buccal or mesio-lingual gingival surface of two teeth with the worst periodontal condition. Two sterilized paper-points (\#20) were placed in gingival sulcus for 20 seconds. Then they were kept in 1.5-ml screw capping microtubes with $200 \mu \mathrm{l}$ of sterilized phosphate buffered saline at $-20^{\circ} \mathrm{C}$.

After vigorous vortexing, the samples were centrifuged for 10 minutes at $13,000 \times \mathrm{g}$ and $4^{\circ} \mathrm{C}$. The pellets were used for bacterial DNA isolation. The genomic DNA was extracted using a genomic DNA extraction kit" following the manufacturer's instruc- tions. The supernatants containing GCF were analyzed for interleukin-1 $\beta$ level using enzyme-linked immunosorbent assay kits** according to the manufacturer's instructions.

Quantitative polymerase chain reaction. For quantitative detection of total bacteria and four periodontopathogens, DNA of the samples was subjected to real-time polymerase chain reaction (PCR) in a sequenced detection system. ${ }^{\dagger \dagger}$ DNA $(1 \mu \mathrm{l})$ was mixed with $10 \mu \mathrm{l}$ of reagent ${ }^{\ddagger \ddagger}$ and $200 \mathrm{nM}$ of each primer in a total reaction volume of $20 \mu \mathrm{l}$. The thermal program chosen was 40 cycles of $95^{\circ} \mathrm{C}$ for 15 seconds, $58^{\circ} \mathrm{C}$ for 15 seconds, and $72^{\circ} \mathrm{C}$ for 33 seconds, with initial denaturation at $95^{\circ} \mathrm{C}$ for 1 minute. All data were analyzed by using the sequenced detection system software. $\S \S$ The sequences of the primers used for real-time PCR were as follows: 5'-TGG AGC ATG TGG TTT AAT TCG A-3' and 5'-TRY GGS ACT TAA SCC RAC A-3' for eubacteria; 5'-TGC AAC TTG CCT TAC AGA GGG-3' and 5'-ACT CGT ATC GCC CGT TAT TC-3' for $P$. gingivalis; 5' -AAT ACC CGA TGT TGT CCA CA-3' and 5'-TTA GCC GGT CCT TAT TCG AA-3' for Prevotella intermedia; 5' ATT GAA ATG TAG ACG ACG GAG AGT-3' and 5'-TTA CCT GTT AGC AAC TGA CAG TCA-3' for Tannerella forsythia (previously $T$. forsythensis); 5' TAA TAC CGA ATG TGC TCA TTT ACA T-3' and 5'-TCA AAG AAG CAT TCC CTC TTC TTC TTA-3' for Treponema denticola. The PCR products were subjected to a melting curve analysis to verify a single amplification product. The copy number of bacterial DNA was calculated with plasmid DNA (pGEM-T) containing 16S ribosomal DNA for each bacterium provided by Dr. J.K. Kook (Chosun University, Kwangju, Korea). Plasmid DNA was 10-fold serially diluted from $10^{\circ}$ to $10^{8}$ copies and subjected to real-time PCR to create a standard curve by plotting the threshold cycles against the copy number of the plasmid DNA as described previously. ${ }^{30}$ Plasmid standards and subgingival samples were run twice in duplicates and the average values were used for calculation of the bacterial load. The detection of DNA below $10^{2}$ cells was regarded as negative. For specificity test of the primers used, DNA of various oral bacteria was included for real-time PCR and non-specific amplification was not detected.

Statistical analysis. The dependent variable is a binary value of either "yes" (a case as PTB [ $<37$ weeks]) or "no" (a control as term birth). Independent variables were collected as explanatory data: 1) demographic information including age; 2) obstetric information

I University of North Carolina No. 15 probe, Hu-Friedy, Chicago, IL.

\# iNtRON Biotechnology, Seongnam, Korea.

* * RED Systems, Minneapolis, MN.

$\dagger \dagger$ ABI PRISM 7300, Applied Biosystems, Foster City, CA.

\$ SYBR Premix Ex Taq, Takara Bio, Otsu City, Japan.

$\S \S$ ABI PRISM 7300, Applied Biosystems. 
including age at the first delivery, the number of pregnancies, parity experience, the history of PTB (yes/no), and the history of abortion (yes/no); 3 ) oral health conditions including periodontal attachment loss ( $\geq 3.5$ $\mathrm{mm}$ ) in $\geq 2$ teeth and $<2$ teeth and BOP (six sites in each tooth, $6 \times 28=168$ sites in total) of $\geq 15 \%$ or $<15 \%$; 4) health-related behaviors during the 12 months before pregnancy including drinking (no/1 to 2 times per month/ $\geq 1$ to 2 times per week), smoking (no/yes), weekly exercise (no/1 to 2 times/ $\geq 3$ times per week), visiting a dental clinic during the last year (no/yes), and scaling (no/yes); and 5) health-related behaviors during pregnancy including weekly light exercise (no/1 to 2 times/ $\geq 3$ times per week), visiting a dental clinic (no/yes), and scaling (no/yes). The counted numbers of microbacterial factors were evaluated in the statistical process including $T$. denticola, $P$. gingivalis, $P$. intermedia, and $T$. forsythia.

Data were entered and analyzed using a statistical program.|l|l The statistical analysis included descriptive statistics as chi-square test for categorical variables, $t$ test for normally distributed continuous variables, and Mann-Whitney $U$ test for abnormally distributed variables; and multivariable logistic regression for adjusted odds ratios. The results of univariate analysis are presented as the number of subjects (percentage) for the chi-square test, mean \pm SD for the $t$ test of normally distributed data, and percentile (25\%, 50\%, and $75 \%)$ for non-parametric variables. For the multivariable logistic analysis, the entering procedure was used for selecting variables. Odds ratios and 95\% confidence intervals were estimated through logistic regression analysis.

\section{RESULTS}

One hundred eighty-seven mothers were invited to this study, of which 15 ( 5 cases and 10 controls) were excluded because of systemic conditions. Of the remaining 172 mothers, 59 who delivered a preterm neonate were assigned to the case group and the other 113 to the control group. Table 1 shows the demographic, obstetric, and oral health features of the study sample. The mean age was not significantly different between the case group (31.7) and the control group (32.1). The difference in the mean age at the first delivery was also not significant $(P=0.107)$. There were also no significant differences in all of the obstetric characteristics including the mean number of pregnancies $(P=0.685)$; the history of abortion $(P=0.627)$; parity experience $(P=0.261)$; and history of PTB $(P=0.111)$.

None of the oral health factors was significantly different between the case and control groups, including $\geq 2$ teeth showing periodontal attachment loss of $\geq 3.5$ $\mathrm{mm}(P=0.318)$ and BOP in $\geq 15 \%$ of total sites $(P=$ 0.663).
Among the health-related behavior factors before pregnancy, the experience of scaling within the last 12 months was the only variable that showed a significant difference between the case and the control groups (Table 2). Twenty-five percent of the case group had experienced scaling before pregnancy, as did $43 \%$ of the control group $(P=0.031)$. For health-related behaviors during pregnancy, $<40 \%$ of the PLBW case group did light exercise weekly $(P=0.119)$.

The adjusting variables were included by stages in the multiple logistic regression analysis: 1) age as demographic information; 2) age at the first delivery, experience of parity, and the history of PTB as obstetric information; and 3) drinking (before pregnancy), smoking, weekly exercise, visiting a dental clinic in the last 12 months, and visiting a dental clinic (during pregnancy) as health-related behavior. In model 3, which included all the potential confounding factors, those who had scaling within 12 months before pregnancy showed a significant difference between the PTB case and control groups $(P=0.039)$ but the difference in scaling during pregnancy was not significant $(P=0.931)$ (Table 3$)$. No association was found between periodontal disease and PTB in this multiple logistic regression analysis with adjusting of any variables $(P=0.256)$.

Few of the microbacterial factors exhibited significant differences between the cases and controls (Table 4). Only P. gingivalis showed a potential difference between the PLBW and the normal range birth weight groups $(P=0.060)$ and the other microbial pathogens $T$. denticola, $P$. intermedia, and $T$. forsythia were not significantly different in the comparison ( $P>0.3$ for all).

\section{DISCUSSION}

Scaling within the last 12 months before pregnancy showed a significant relationship with the PTB cases in this study but oral health conditions, such as periodontitis and gingivitis, did not show a significant relationship. Among the microbacterial factors, only $P$. gingivalis had slightly different distribution between the PLBW case and control groups.

Health-related behaviors did not show any significant relationship with PLBW in this study except scaling within the last 12 months before pregnancy. Those who received scaling services before pregnancy were less likely to have PLBW. Visiting a dental clinic can be interpreted as a similar indicator that presents the pattern of use of dental services. However, there was no statistical difference in the percentage of those who visited a dental clinic before and during pregnancy between the case and the control groups. The gap between the two indicators might be presumed to be

||| SPSS for Windows, Version 12.0, SPSS, Chicago, IL. 
Table I.

\section{Demographic, Obstetric, and Oral Health Conditions $(n=172)$}

\begin{tabular}{|c|c|c|c|}
\hline Variables & Preterm Cases $(n=59)$ & Controls $(n=1 \mid 3)$ & $P$ Value* \\
\hline Age range (years) $^{\dagger}$ & $31.66 \pm 4.37$ ( 19 to 43$)$ & $32.09 \pm 3.84$ ( 19 to 43$)$ & 0.509 \\
\hline $\begin{array}{l}\text { Obstetric information } \\
\text { Age (years) at first delivery } \\
\text { Number of pregnanciest }\end{array}$ & $\begin{array}{r}29.59 \pm 3.69 \\
1.24 \pm 1.18\end{array}$ & $\begin{array}{r}30.55 \pm 3.69 \\
1.15 \pm 1.40\end{array}$ & $\begin{array}{l}0.107 \\
0.685\end{array}$ \\
\hline $\begin{array}{l}\text { Parity experience } \\
\text { Yes } \\
\text { No }\end{array}$ & $\begin{array}{l}32(54.2) \\
27(45.8)\end{array}$ & $\begin{array}{l}50(44.2) \\
63(55.8)\end{array}$ & 0.261 \\
\hline $\begin{array}{l}\text { History of preterm birth } \\
\text { Yes } \\
\text { No }\end{array}$ & $\begin{array}{r}7(11.9) \\
52(88.1)\end{array}$ & $\begin{array}{c}5(4.4) \\
108(95.6)\end{array}$ & 0.111 \\
\hline $\begin{array}{l}\text { History of abortion } \\
\text { Yes } \\
\text { No }\end{array}$ & $\begin{array}{l}26(44.1) \\
33(55.9)\end{array}$ & $\begin{array}{l}45(39.8) \\
68(60.2)\end{array}$ & 0.627 \\
\hline $\begin{array}{l}\text { Oral health conditions } \\
\text { Number of missing teeth } \\
\text { Periodontal attachment loss } \\
\text { ( } \geq 3.5 \mathrm{~mm}) \\
\geq 2 \text { teeth } \\
<2 \text { teeth }\end{array}$ & $\begin{array}{l}24(40.7) \\
35(59.3)\end{array}$ & $\begin{array}{l}37(32.7) \\
76(67.3)\end{array}$ & 0.318 \\
\hline $\begin{array}{l}\text { BOP (\% in total sites) } \\
\geq 15 \% \\
<15 \%\end{array}$ & $\begin{array}{r}8(13.6) \\
51(86.4)\end{array}$ & $\begin{array}{l}19(16.8) \\
94(83.2)\end{array}$ & 0.663 \\
\hline
\end{tabular}

* $P$ value by chi-square test.

$\uparrow \mathrm{SD}$ determined by $t$ test.

that scaling experience exhibits the pattern of oral health care more accurately. In Korea, not many individuals get regular examinations for oral health and visit a dental clinic mostly for treatment rather than health care. Those who had scaling can be explained to have the tendency of going to the dental clinic for preventive initiatives. As shown in the results, the control group was better in managing their health compared to the case group.

Some research revealed results similar to ours, reporting no difference in periodontal conditions between PLBW and term birth with normal weight. ${ }^{22,25-27}$ However, most previous studies concluded that there is a causal relationship between periodontal conditions and the likelihood of PLBW. ${ }^{2,10,16,17,21,23,24,31-34 ~ R e-~}$ cently, Finnish researchers argued that the combined effect of multiple oral infections was significantly associated with PTB. ${ }^{35}$ The oral inflammatory burden index based on the clinical findings of gingival BOP, probing depth, and the presence of dental calculus and mouth ulcers was significantly associated with PTB after adjusting confounding factors. ${ }^{35}$

There could be some explanations for the specific result of this present study. First, the high maternal age may help explain the differences in periodontitis and gingivitis between the case and control groups even after adjusting other compounding factors in our final results. The average age at the first childbirth was early to mid-20s in most of the other studies. ${ }^{10,15-18,20,27,33,36,37}$ According to a National Fertility, Family Health and Welfare survey in Korea, the mean age of women at marriage was 24.1, and the mean age at first delivery was $25.3 .^{7}$ The mean ages of our study sample groups were high, around 32 years old. The mean age at first delivery was also high, about 30 years old. A possible reason why the mean age of our sample was so high can be older mothers' tendency of using health care services. The participants were recruited in the gynecology clinic of a tertiary hospital, which is well equipped for emergencies. An advanced maternal age may cause mothers to seek a fully equipped hospital. In the Korean National Oral Health Survey, $21.6 \%$ of 25 - to 29 -year-old women were found to have bleeding on their gums, while the percentage was relatively lower at $13.8 \%$ in 30- to 34-year-old women. ${ }^{38} \mathrm{~A}$ similar discrepancy was found in the prevalence of 4- to 5-mm deep pockets, $1.9 \%$ in 25 - to 29 -year-old women and $5.9 \%$ in 
Table 2.

\section{Health-Related Behaviors of the Study Sample Before and During Pregnancy $(\mathrm{n}=172)$}

\begin{tabular}{|c|c|c|c|}
\hline Variables & $\begin{array}{l}\text { Preterm Cases } \\
\qquad(n=59)\end{array}$ & $\begin{array}{l}\text { Controls } \\
(n=113)\end{array}$ & P Value* \\
\hline \multicolumn{4}{|c|}{$\begin{array}{l}\text { Health-related behavior before pregnancy } \\
\text { Drinking }\end{array}$} \\
\hline No & $34(57.6)$ & $69(61.1)$ & \multirow[t]{3}{*}{0.494} \\
\hline I to 2 times/month & $19(32.2)$ & $38(33.6)$ & \\
\hline$\geq 1$ to 2 times/week & $6(10.2)$ & $6(5.3)$ & \\
\hline \multicolumn{4}{|l|}{ Smoking } \\
\hline No & $53(89.8)$ & $106(94.6)$ & \multirow[t]{2}{*}{0.344} \\
\hline Yes & $6(10.2)$ & $6(5.4)$ & \\
\hline \multicolumn{4}{|l|}{ Weekly exercise } \\
\hline & $38(64.4)$ & $63(55.8)$ & \multirow[t]{3}{*}{0.529} \\
\hline I to 2 times & $15(25.4)$ & $34(30.1)$ & \\
\hline$\geq 3$ times & $6(10.2)$ & $16(14.2)$ & \\
\hline \multicolumn{3}{|c|}{ Visiting a dental clinic in last 12 months } & \multirow{3}{*}{0.629} \\
\hline No & $27(45.8)$ & $47(41.6)$ & \\
\hline Yes & $32(54.2)$ & $66(58.4)$ & \\
\hline \multicolumn{3}{|c|}{ Scaling in last 12 months } & \multirow{3}{*}{0.031} \\
\hline No & $44(74.6)$ & $65(57.5)$ & \\
\hline Yes & $15(25.4)$ & $48(42.5)$ & \\
\hline \multicolumn{3}{|c|}{$\begin{array}{l}\text { Health-related behavior during pregnancy } \\
\text { Light weekly exercise }\end{array}$} & \multirow{4}{*}{0.119} \\
\hline No & $31(52.5)$ & $41(36.3)$ & \\
\hline I to 2 times & $20(33.9)$ & $53(46.9)$ & \\
\hline$\geq 3$ times & $8(13.6)$ & $19(16.8)$ & \\
\hline \multicolumn{3}{|l|}{ Visiting a dental clinic } & \multirow{3}{*}{0.862} \\
\hline No & $41(69.5)$ & $80(70.8)$ & \\
\hline Yes & $18(30.5)$ & $33(29.2)$ & \\
\hline \multicolumn{3}{|l|}{ Scaling } & \multirow{3}{*}{0.831} \\
\hline No & $50(84.7)$ & $93(82.3)$ & \\
\hline Yes & $9(15.3)$ & $20(17.7)$ & \\
\hline
\end{tabular}

* $P$ value by chi-square test.

30- to 34-year-old women. Second, Xiong et al. ${ }^{39}$ mentioned that the conclusions of previous research were different among countries. Studies showing a significant relationship between periodontal disease and adverse pregnancy outcomes tended to be conducted with groups economically disadvantaged or underprivileged in other ways. They suggested that the differences observed between countries resulted from socioeconomic conditions on the national level and the ease of access to dental care. Periodontal conditions may be related to PLBW through common risk factors rather than through any direct causal effects. There are well-known gaps in health including oral health between social and economic groups. The dif-
Table 3.

\section{Odds Ratios and 95\% Confidence Intervals of PLBW Deliveries by Oral Health and Related Behaviors}

\begin{tabular}{|c|c|c|c|}
\hline Variables & & $\begin{array}{c}\text { Odds Ratio } \\
\text { (95\% confidence } \\
\text { interval) }\end{array}$ & $\begin{array}{c}P \\
\text { Value }\end{array}$ \\
\hline \multicolumn{4}{|c|}{ Health-related behavior } \\
\hline \multirow{3}{*}{$\begin{array}{l}\text { Scaling } \\
\text { within } 12 \text { months } \\
\text { before pregnancy }\end{array}$} & Model I & $0.46(0.23$ to 0.93$)$ & 0.030 \\
\hline & Model 2 & $0.48(0.23$ to 0.99$)$ & 0.048 \\
\hline & Model 3 & $0.45(0.21$ to 0.96$)$ & 0.039 \\
\hline \multirow{3}{*}{$\begin{array}{l}\text { Scaling during } \\
\text { pregnancy }\end{array}$} & Model I & 0.85 (0.36 to 2.02$)$ & 0.720 \\
\hline & Model 2 & 0.85 (0.36 to 2.22$)$ & 0.741 \\
\hline & Model 3 & 0.96 (0.36 to 2.57$)$ & 0.931 \\
\hline \multicolumn{4}{|c|}{ Oral health conditions } \\
\hline \multirow{3}{*}{$\begin{array}{l}\text { Periodontal } \\
\text { attachment } \\
\text { loss ( } \geq 3.5 \mathrm{~mm} \text {, } \\
\geq 2 \text { teeth) }\end{array}$} & Model I & $1.43(0.74$ to 2.74$)$ & 0.287 \\
\hline & Model 2 & $1.58(0.79$ to 3.16$)$ & 0.195 \\
\hline & Model 3 & 1.50 (0.74 to 3.03$)$ & 0.256 \\
\hline
\end{tabular}

Model 1: Adjusting for age.

Model 2: Adjusting for age, age at first delivery, experience of parity, and history of preterm birth.

Model 3: Adjusting for age; age at first delivery; experience of parity; history of preterm birth; drinking (before pregnancy); smoking; weekly exercise; visiting a dental clinic in last 12 months; and visiting a dental clinic during pregnancy.

ferences are found across social classes in the same country ${ }^{40,41}$ and across countries. ${ }^{42}$ However, these differences among countries between periodontal disease and PLBW have not been fully demonstrated. More research is necessary including a multi-level meta-analysis for international comparisons.

Katz et al. ${ }^{43}$ examined microbacterial conditions in PLBW. They reported that $P$. gingivalis antigens are more frequent and more intense in chorioamnionitis placentas than in normal placentas. It can be assumed that severe periodontal disease with increased bacterial load, such as $P$. gingivalis, is related with preterm delivery. However, Novak et al. ${ }^{44}$ suggested that the baseline subgingival bacterial profiles do not differ significantly between women who delivered preterm infants and those of full-term. After a periodontal intervention, the numbers and proportions of subgingival periodontal pathogens were significantly reduced and clinical improvement was also significant, but microbiologic changes associated with term or preterm delivery were not statistically significantly different. ${ }^{44}$ A possible clue to the insignificant relationship between microbacteria and non-surgical periodontal treatment as an intervention was given by a study from Finland. ${ }^{35}$ The authors suggested that the obstetrics and periodontal therapy might have been provided too late to the pregnant women and left other potential inflammatory sources untreated. This 
Table 4.

\section{The Differences of Microbacterial Distribution Between PLBW Case and the Control Groups $(n=43)$}

\begin{tabular}{lcccccc}
\hline Microbacterial Factors & \multicolumn{3}{c}{ Preterm Cases $(n=22)$} & \multicolumn{2}{c}{ Controls $(n=21)$} & $P$ Value* \\
\hline Treponema denticola & 0 & $6,005.9$ & $19,5157.1$ & 0 & $15,569.2$ & $210,729.0$ \\
Porphyromonas gingivalis & 0 & $21,100.1$ & $902,959.5$ & 0 & 0 & $3,168.3$ \\
Prevotella intermedia & 0 & 0 & $173,568.5$ & 0 & 0 & $12,310.3$ \\
Tannerella forsythia & 0 & 0 & 639.1 & 0 & 0 & 4.060 \\
\hline
\end{tabular}

* $P$ value by Mann-Whitney U test for non-parametric distribution (25\%,50\%, and $75 \%)$.

explanation corresponded to our results that only scaling within 12 months before pregnancy had a significant difference between the PTB and control groups. It may be presumed that oral health promotion before pregnancy, such as periodontal status control and preventive oral health care, is more important than that during pregnancy care.

Even though this study is strengthened by the examiner-masked design, case-control studies often show some limitations, such as selection bias in control sampling and recall bias in interviewing or questioning. The selection of hospital-based controls may also be problematic compared to selection from the community. Another shortcoming of these case-control studies is that some variables not included in this study (e.g., socioeconomic status of the study samples) may explain changes in PLBW. ${ }^{45}$ In addition, a larger sample size could make the associations clearer even though the sample size had been estimated before the study. Studies on periodontal effects on PLBW with matched cases and controls have been relatively rare in Asian countries, and this is the first study in East Asia. More comprehensive designs including various risk factors or indicators and confounders need to be taken into account. In the microbacterial experiments, only a part of the sample was included even though the sampling selection methodology followed the principles presented in the methods section of this study. A reason for this limited selection came from the framework design including the amount of financial support available. Fully designed case and control selections that match certain demographic and socioeconomic conditions are recommended to overcome these problems. Generally, most of the studies applied interventions or examinations a few months before delivery. Cohort studies in different countries following-up subjects from marriage through pregnancy to delivery are necessary.

\section{CONCLUSION}

There was a significant difference in scaling experience within 12 months before pregnancy, and $P$. gingivalis showed a marginal difference between the PTB group and the control group, but clinical periodontal conditions showed no association with PTB.

\section{ACKNOWLEDGMENTS}

This work was supported by the Korea Research Foundation Grant funded by the Korean Government (MOEHRD, Basic Research Promotion Fund, Seoul, Korea; E00230). The authors report no conflicts of interest related to this study.

\section{REFERENCES}

1. World Health Organization. The incidence of low birth weight: An update. Wkly Epidemiol Rec 1984;59:205211. Available at: http://whqlibdoc.who.int/wer/WHO_ WER_1984/WER1984_59_205-212\%20(N\%C2\%B027). pdf. Accessed March 3, 2009.

2. Khader YS, Ta'ani Q. Periodontal diseases and the risk of preterm birth and low birth weight: A meta-analysis. J Periodontol 2005;76:161-165.

3. Kramer MS. Determinants of low birth weight: Methodological assessment and meta-analysis. Bull World Health Organ 1987;65:663-737.

4. McCormick MC. The contribution of low birth weight to infant mortality and childhood morbidity. NEngl JMed 1985;312:82-90.

5. United Nation's Children's Fund, World Health Organization. Low Birthweight: Country, Regional and Global Estimates. New York: UNICEF; 2004: 7-9.

6. Koo YH, Kim SK, Shim JY, Won HS, Lee PR, Kim A. Analysis of preterm birth rate based on birth certificate data: From 1995 to 2003 (in Korean). Korean Journal of Obstetrics and Gynecology 2006;49:1855-1865.

7. Korea Institute of Health and Social Affairs. The trends in fertility rate. In: The Survey of the National Fertility, Family Health, and Welfare in Korea 2006. Seoul: Korea Institute of Health and Social Affairs; 2006:173-177.

8. Heyborne KD, Witkin SS, McGregor JA. Tumor necrosis factor-alpha in midtrimester amniotic fluid is associated with impaired intrauterine fetal growth. Am J Obstet Gynecol 1992;167:920-925.

9. Jarvis MJ, Goddard E, Higgins V, Feyerabend C, Bryant A, Cook DG. Children's exposure to passive smoking in England since the 1980s: Cotinine evidence from population surveys. BMJ 2000;321:343-345. 
10. Moliterno LF, Monteiro B, Figueredo CM, Fischer RG. Association between periodontitis and low birth weight: A case-control study. J Clin Periodontol 2005; 32:886-890.

11. Peacock JL, Bland JM, Anderson HR. Preterm delivery: Effects of socioeconomic factors, psychological stress, smoking, alcohol, and caffeine. BMJ 1995;311: 531-535.

12. Rotta NT, Cunha GB. Prenatal exposure to cocaine: Review of the neurobehavioral effects (in Portuguese). J Pediatr (Rio J) 2000;76:179-184.

13. McGregor JA, French JI, Lawellin D, Todd JK. Preterm birth and infection: Pathogenic possibilities. Am J Reprod Immunol Microbiol 1988;16:123-132.

14. Collins JG, Smith MA, Arnold RR, Offenbacher S. Effects of Escherichia coli and Porphyromonas gingivalis lipopolysaccharide on pregnancy outcome in the golden hamster. Infect Immun 1994;62:46524655.

15. Dasanayake AP, Boyd D, Madianos PN, Offenbacher S, Hills E. The association between Porphyromonas gingivalis-specific maternal serum IgG and low birth weight. J Periodontol 2001;72:1491-1497.

16. Jeffcoat MK, Geurs NC, Reddy MS, Cliver SP, Goldenberg RL, Hauth JC. Periodontal infection and preterm birth: Results of a prospective study. Dent Assoc 2001;132:875-880.

17. Lopez NJ, Smith PC, Gutierrez J. Periodontal therapy may reduce the risk of preterm low birth weight in women with periodontal disease: A randomized controlled trial. J Periodontol 2002;73:911-924.

18. Mitchell-Lewis D, Engebretson SP, Chen J, Lamster IB, Papapanou PN. Periodontal infections and preterm birth: Early findings from a cohort of young minority women in New York. Eur J Oral Sci 2001; 109:34-39.

19. Offenbacher S, Katz V, Fertik G, et al. Periodontal infection as a possible risk factor for preterm low birth weight. J Periodontol 1996;67(Suppl.10):1103-1113.

20. Buduneli N, Baylas H, Buduneli E, Turkoglu O, Kose T, Dahlen G. Periodontal infections and pre-term low birth weight: A case-control study. $\mathrm{J}$ Clin Periodontol 2005;32:174-181.

21. Lopez NJ, Smith PC, Gutierrez J. Higher risk of preterm birth and low birth weight in women with periodontal disease. J Dent Res 2002;81:58-63.

22. Davenport ES, Williams CE, Sterne JA, Murad S, Sivapathasundram V, Curtis MA. Maternal periodontal disease and preterm low birthweight: Case-control study. J Dent Res 2002;81:313-318.

23. Hasegawa K, Furuichi Y, Shimotsu A, et al. Associations between systemic status, periodontal status, serum cytokine levels, and delivery outcomes in pregnant women with a diagnosis of threatened premature labor. $J$ Periodontol 2003;74:17641770.

24. Moreu G, Tellez L, Gonzalez-Jaranay M. Relationship between maternal periodontal disease and low-birthweight pre-term infants. J Clin Periodontol 2005;32: 622-627

25. Lunardelli AN, Peres MA. Is there an association between periodontal disease, prematurity and low birth weight? A population-based study. J Clin Periodontol 2005;32:938-946.

26. Bassani DG, Olinto MT, Kreiger N. Periodontal disease and perinatal outcomes: A case-control study. $\underline{J}$ Clin Periodontol 2007;34:31-39.
27. Rajapakse PS, Nagarathne M, Chandrasekra KB, Dasanayake AP. Periodontal disease and prematurity among non-smoking Sri Lankan women. J Dent Res 2005;84:274-277.

28. Offenbacher S, Beck JD, Jared HL, et al. Effects of periodontal therapy on rate of preterm delivery: A randomized controlled trial. Obstet Gynecol 2009; 114 : 551-559.

29. Dupont WD, Plummer WD Jr. Power and sample size calculations. A review and computer program. Control Clin Trials 1990;11:116-128.

30. Nonnenmacher C, Dalpke A, Mutters R, Heeg K. Quantitative detection of periodontopathogens by real-time PCR. J Microbiol Methods 2004;59:117125.

31. Choi EC, Ku Y, Rhyu IC, et al. Relationship between preterm low birth weight and periodontal disease activity in pregnancy (in Korean). The Journal of Korean Academy of Periodontology 2000;30:111120.

32. Contreras A, Herrera JA, Soto JE, Arce RM, Jaramillo A, Botero JE. Periodontitis is associated with preeclampsia in pregnant women. JPeriodontol 2006;77: 182-188.

33. Lopez NJ, Da Silva I, Ipinza J, Gutierrez J. Periodontal therapy reduces the rate of preterm low birth weight in women with pregnancy-associated gingivitis. J Periodontol 2005;76:2144-2153.

34. Mokeem SA, Molla GN, Al-Jewair TS. The prevalence and relationship between periodontal disease and preterm low birth weight infants at King Khalid University Hospital in Riyadh, Saudi Arabia. J Contemp Dent Pract 2004;5:40-56.

35. Heimonen A, Janket SJ, Kaaja R, Ackerson LK, Muthukrishnan P, Meurman JH. Oral inflammatory burden and preterm birth. J Periodontol 2009;80: 884-891.

36. Lin D, Moss K, Beck JD, Hefti A, Offenbacher S. Persistently high levels of periodontal pathogens associated with preterm pregnancy outcome. $\mathrm{J}$ Periodontol 2007;78:833-841.

37. Offenbacher S, Lin D, Strauss R, et al. Effects of periodontal therapy during pregnancy on periodontal status, biologic parameters, and pregnancy outcomes: A pilot study. J Periodontol 2006;77: 2011-2024.

38. Ministry of Health Welfare and Family Affairs. 2006 Korea National Oral Health Survey. In: National Oral Health Survey. Seoul: Ministry of Health Welfare and Family Affairs; 2007:252.

39. Xiong X, Buekens P, Fraser WD, Beck J, Offenbacher S. Periodontal disease and adverse pregnancy outcomes: A systematic review. BJOG 2006;113:135143.

40. Berkman LF. Kawachi IO. Socioeconomic position. In: Social Epidemiology. New York: Oxford University Press; 2000:13-35.

41. Marmot MG, Wilkinson RG. The life course, the social gradient, and health. In: Social Determinants of Health. Oxford: Oxford University Press; 2006:54-77.

42. Petersen PE, Bourgeois D, Ogawa H, Estupinan-Day $\mathrm{S}$, Ndiaye $\mathrm{C}$. The global burden of oral diseases and risks to oral health. Bull World Health Organ 2005;83: 661-669.

43. Katz J, Chegini N, Shiverick KT, Lamont RJ. Localization of $P$. gingivalis in preterm delivery placenta. J Dent Res 2009;88:575-578. 
44. Novak MJ, Novak KF, Hodges JS, et al. Periodontal bacterial profiles in pregnant women: Response to treatment and associations with birth outcomes in the obstetrics and periodontal therapy (OPT) study. $\underline{J}$ Periodontol 2008;79:1870-1879.

45. Bowling A. The principles of research. In: Research Methods in Health: Investigating Health and Health Services. Philadelphia: Open University Press; 2002:153-156.
Correspondence: Dr. Kwang-Hak Bae, Department of Preventive and Public Health Dentistry, School of Dentistry, Seoul National University, 28 Yeongeuon-dong, Jongno-gu, Seoul, 110-749, Korea (South). Fax: 82-2765-1722; e-mail: baekh@snu.ac.kr.

Submitted December 1, 2009; accepted for publication January 27, 2010. 